medRxiv preprint doi: https://doi.org/10.1101/2020.11.25.20238865; this version posted November 29, 2020. The copyright holder for this preprint (which was not certified by peer review) is the author/funder, who has granted medRxiv a license to display the preprint in perpetuity.

It is made available under a CC-BY-ND 4.0 International license .

\title{
Large-Scale Meta-Analysis of Potential Biomarkers for Treatment Response to Anti-PD- 1/PD-L1 Immune Checkpoint Inhibitors
}

Arshiya Mariam ${ }^{1}$, Suneel Kamath ${ }^{2}$, Kimberly Schveder ${ }^{1}$, Howard L. McLeod ${ }^{3}$, Daniel M.

Rotroff ${ }^{1,4, *}$

1. Department of Quantitative Health Sciences, Lerner Research Institute, Cleveland Clinic, $\mathrm{OH}, \mathrm{USA}$

2. Taussig Cancer Institute, Cleveland Clinic, Cleveland, OH, USA

3. University of South Florida Taneja College of Pharmacy, Tampa, FL, USA

11 4. Cleveland Clinic Lerner College of Medicine, Case Western Reserve University, Cleveland, $\mathrm{OH}, \mathrm{USA}$

Arshiya Mariam: mariama@ccf.org

16 Suneel Kamath: kamaths@ccf.org

17 Kimberly Schveder: kaschveder@gmail.com

18 Howard L. McLeod: hmcleod1965@gmail.com

19 Daniel M. Rotroff: rotrofd@ccf.org

*Corresponding Author:

Daniel M. Rotroff, PhD, MSPH

Department of Quantitative Health Sciences

Lerner Research Institute

Cleveland Clinic

9500 Euclid Avenue,

26 JJN3-01,

28 Cleveland, $\mathrm{OH} 44195$, USA

29 Phone: 216-444-3399

30 Email: rotrofd@ccf.org

32 Running Title: Potential Biomarkers for Treatment Response to Anti-PD-1/PD-L1 Immune

33 Checkpoint Inhibitors

Keywords: Tumor Biomarkers, Immunotherapy, Genetic Markers, Programmed Cell Death 1 Receptor 
medRxiv preprint doi: https://doi.org/10.1101/2020.11.25.20238865; this version posted November 29, 2020. The copyright holder for this

\section{Abstract}

38 Immune checkpoint inhibitors (ICIs) blocking programmed death receptor 1 or its ligand (anti-

39 PD-1/PD-L1) are a burgeoning class of promising cancer treatments. However, not all patients

40 respond to these treatments. Although studies have suggested potential biomarkers to predict

41 patients likely to respond to treatment, no consensus biomarker has been identified. Here, 95

42 peer-reviewed studies representing 18,978 subjects across 15 cancer types were meta-analyzed to

43 determine biomarkers that best predicted ICI response within and across cancers. Performance

44 was assessed using the sensitivity, specificity, area under the receiver operating characteristic

45 curve, and others. Across all cancers, multimodal biomarkers and tumor mutational burden

46 discriminated ICI response better than PD-L1 immunohistochemistry assays (IHC) $(P=.04)$ with

47 sensitivities of 0.57 and 0.70 and specificities of 0.76 and 0.53 , respectively. Marginal

48 improvements were also observed for nascent microbiome biomarkers compared to IHC $(P=.06)$.

49 Current ICI biomarker performances indicate that additional research is needed to develop highly

50 accurate and precise biomarkers for widespread clinical adoption.

Introduction

Immune checkpoint inhibitors (ICIs) have become a cornerstone of cancer therapy across

54 multiple histologies. ${ }^{1,2}$ ICIs blocking programmed death protein receptor $1(\mathrm{PD}-1)$ or its ligand

55 (PD-L1) are at the forefront of clinical implementation. These therapies re-activate the immune

56 response to tumor cells by inhibiting the interaction of PD-L1 and PD-1, and multiple studies

57 have demonstrated their clinical benefit over standard treatments. ${ }^{3-7}$ Although ICIs show

58 evidence of durable clinical benefit for individuals that respond, a systematic meta-analysis

59 estimates that the overall response rate to anti-PD-1/anti-PD-L1 therapies is $24 \%(95 \% \mathrm{CI}=$

$6021 \%-28 \%)^{2}$ In addition, approximately 16\% (95\% CI: $\left.12 \%-21 \%\right)$ of patients experience 
61 significant toxicity, including colitis, pneumonitis and endocrine organ dysfunction. ${ }^{2}$ For these

62 reasons, it is critical that robust predictive biomarkers are identified that can guide clinical

63 decision making.

64 Many studies have explored whether PD-L1 or PD-1 protein expression ${ }^{8-11}$, tumor

65 mutational burden ${ }^{12-16}$, specific somatic mutations (e.g., KRAS, BRAF) ${ }^{2,17-22}$ and more recently,

66 immune related adverse events ${ }^{23}$ can discriminate between responders and non-responders to

67 anti-PD-1/anti-PD-L1 immunotherapies. However, results from these studies are often

68 inconsistent or inconclusive. For example, Bellmunt et al. reported a PD-L1 expression threshold

69 above $10 \%$ discriminated patients with urothelial bladder cancer ${ }^{24}$; whereas Massard et al.

70 reported a threshold of $25 \%$ for the same cancer type. ${ }^{25}$ Differences in patient populations,

71 samples collection, sample processing, technological platform, biomarker thresholds and the ICI

72 used may all impact variability across studies. In addition to methodological differences, many

73 ICI studies have limited sample sizes that may impact statistical power for discovering

74 biomarkers. Although most reviews aim to qualitatively condense information across studies, the

75 predictive accuracies of biomarkers are not always summarized in a quantitative manner ${ }^{26,27}$.

76 Relevant statistical summaries for these biomarkers can be ascertained from the literature using

77 meta-analysis, and this approach has been gaining traction as an approach to develop consensus

78 around important clinical questions ${ }^{2,28}$. An additional benefit of meta-analyses is that biomarkers

79 can be concurrently evaluated across different treatments, threshold values and cancer types.

80 Here we conducted the largest meta-analysis of predictive biomarkers for ICI therapy to date,

81 including 95 peer-reviewed studies representing data from 18,978 patients. We also investigated

82 whether the microbiome or immune mediated adverse events show evidence of biomarker

83 potential. Furthermore, whereas most studies qualitatively assess area under the receiver 
medRxiv preprint doi: https://doi.org/10.1101/2020.11.25.20238865; this version posted November 29, 2020. The copyright holder for this preprint (which was not certified by peer review) is the author/funder, who has granted medRxiv a license to display the preprint in perpetuity.

It is made available under a CC-BY-ND 4.0 International license .

84 operating characteristic curve (AUCs) performance, we evaluated whether the AUCs for

85 biomarker performance were statistically different from one another. The objective of this study

86 was to provide a comprehensive evaluation of the current state of predictive accuracies of the

87 most commonly considered biomarkers for ICI treatment response.

88 Results

89 After performing quality control, a total of 95 studies met the inclusion criteria for

90 analysis, and all studies were conducted between the years 2010-2020. Objective response rate

91 was reported in $85.27 \%$ of studies, and clinical benefit (CB) and six-months progression free

92 survival (PFS) were reported in $8.42 \%$ and $6.30 \%$ of studies, respectively. The counts for

93 reported studies are provided in Supplementary Figure 1. The most frequent cancer types in the

94 dataset were non-small -cell lung cancer (27.40\%) and melanoma (23.20\%), and the most

95 frequently explored biomarker for all cancer types was PD-L1 expression (Supplementary Figure

96 1). Below we present the meta-analysis results by cancer-type (Fig. 1 and Table 1) followed by

97 an overall characterization across cancer types for each biomarker (Fig. 2 and Table 2). The

98 meta-analysis results across all cancer types and other analyses are shown in Supplemental Table

99 5-8. All of the included studies are listed in Supplementary Table 2 and Supplementary Table 9.

100 Non-small-cell lung cancer (NSCLC): In studies of NSCLC, PD-L1 expression (N=26),

101 tumor mutational burden (TMB) $(\mathrm{N}=9)$, Gene expression profiles (GEP) $(\mathrm{N}=1)$ and multimodal

102 biomarkers $(\mathrm{N}=3)$ were investigated for prognostic biomarker potential (Supplementary Table 5).

103 TMB and PD-L1 expression classified responders better than chance $(P<.05$ for both) (Fig. 1).

104 The gAUC estimates for TMB, PD-L1 expression and multimodal biomarker were 0.70 (95\%

105 CI: $0.60-0.74), 0.61$ (95\% CI: 0.56-0.66) and 0.71 (95\% CI: 0.43-0.90), respectively. GEP was 
106

107

108

109

not meta-analyzed because only a single study was available, and this study classified responders with a sensitivity and specificity of 0.49 and 0.61 , respectively.

Melanoma: In studies of melanoma, fluorescent multiplex immunohistochemistry assays $(\mathrm{mIHC} / \mathrm{IF})(\mathrm{N}=2$, global area under the receiver operating characteristic curve $(\mathrm{gAUC})=0.82$, 95\% CI: 0.53-0.93), PD-L1 immunohistochemistry (IHC) $(\mathrm{N}=14$, gAUC $=0.60,95 \%$ CI: $0.53-$ $0.66)$ and multimodal biomarkers $(\mathrm{N}=2, \mathrm{gAUC}=0.65,95 \% C I: 0.56-0.73)$ were significantly more accurate than random assignment $(\mathrm{gAUC}=0.50)(P<.05$ for all). Conversely TMB had the lowest gAUC of 0.37 (95\% CI: 0.33-0.83, N=4) (Fig. 1). Furthermore, bootstrap hypothesis testing showed that the gAUC estimate for TMB was significantly lower than PD-L1 IHC, multimodal biomarkers, mIHC/IF and microbiome (Supplementary Fig. 2). The three most accurate biomarkers had both similar sensitivities in capturing responders and misclassification rate (Fig. 1). The greatest specificity estimate value of 0.90 was observed for microbiome $(95 \%$ $C I$ : $0.50-0.99)$. In addition to microbiome, only multimodal biomarker captured more nonresponders than 0.50 (specificity $=0.62,95 \% C I: 0.54-0.70)$.

Biomarker efficacy across cancers: The prognostic efficacy of each biomarker was evaluated for 1) the five biomarkers with greatest cohort sizes (i.e., PD-L1 IHC, TMB, adverse events of special interest (AEs), International Metastatic RCC Database Consortium risk score $(\text { IMDC) })^{29,30}$, GEP and multimodal biomarkers), 2) multimodal and mIHC/IF biomarkers and 3) for specific targeted somatic mutations. Because presence of a targeted somatic mutation can be representative of either an increased or reduced likelihood to benefit from ICI treatment, each mutation was meta-analyzed evaluating both possibilities (Fig. 3).

Frequently explored biomarkers: Across all evaluated cancer types, the performance for biomarkers with cohort sizes $>500$ were investigated. These were PD-L1 IHC $(\mathrm{N}=13,601$ 
medRxiv preprint doi: https://doi.org/10.1101/2020.11.25.20238865; this version posted November 29, 2020. The copyright holder for this preprint (which was not certified by peer review) is the author/funder, who has granted medRxiv a license to display the preprint in perpetuity.

It is made available under a CC-BY-ND 4.0 International license .

129 subjects), AEs $(\mathrm{N}=1,747)$, TMB $(\mathrm{N}=1,724)$, GEP $(\mathrm{N}=775)$, multimodal biomarker $(\mathrm{N}=559)$ and

130 IMDC $(\mathrm{N}=547)$. All biomarkers other than adverse events were meta-analyzed, because adverse

131 events all came from a single published report ${ }^{23}$. The greatest and lowest gAUC values were

132 observed for multimodal biomarker $(\mathrm{gAUC}=0.70,95 \% \mathrm{CI}: 0.61-0.76)$ and GEP (gAUC=0.56,

133 95\% CI: 0.49-0.65), respectively. Multimodal biomarkers and TMB were significantly more

134 accurate than PD-L1 IHC $(P=.04)$ (Supplementary Fig. 6). GEP was most sensitive to responders

135 (sensitivity=0.71, 95\% CI: 0.55-0.84) whereas AEs were the least sensitive (sensitivity=0.36).

136 Multimodal biomarker and TMB had sensitivity estimates of 0.57 (95\% CI: $0.47-0.67$ ) and 0.70

137 (95\% CI: $0.63-0.77)$, respectively. In addition to having the second greatest estimated sensitivity,

138 accurate classification of non-responders by TMB (Specificity $=0.53,95 \%$ CI: 0.46-0.60) was

139 second only to multimodal biomarker (Specificity $=0.76,95 \%$ CI: $0.66-0.83$ ). The complete

140 results are shown in Fig. 2.

$141 \quad$ Multimodal and mIHC/IF biomarkers: Five studies were available that investigated

142 multimodal biomarkers, and three studies were available that investigated mIHC/IF. The number

143 of individuals for each biomarker was 559 and 177, respectively. The meta-analyzed gAUC

144 estimate indicated that both biomarkers performed better than random chance $(\mathrm{gAUC}>0.50)$ for

145 discriminating treatment responders $(P<.05)$. However, the gAUC estimate for multimodal

146 biomarkers (gAUC $=0.70,95 \%$ CI: 0.61-0.76) was not significantly different than the $\mathrm{mIHC} / \mathrm{IF}$

147 estimate $(\mathrm{gAUC}=0.81,95 \%$ CI: $0.58-0.91)(P>.05) . \mathrm{mIHC} / \mathrm{IF}$ was a more sensitive biomarker

148 (sensitivity $=0.85,95 \%$ CI: $0.68-0.94)$ compared to multimodal (sensitivity $=0.57,95 \%$ CI: 0.47 -

149 0.67). In addition, no significant differences were observed in the gAUC values of either of these

150 biomarkers and TMB (Table 2) $(P>.05)$. However, multimodal biomarkers classified patient 
medRxiv preprint doi: https://doi.org/10.1101/2020.11.25.20238865; this version posted November 29, 2020. The copyright holder for this preprint (which was not certified by peer review) is the author/funder, who has granted medRxiv a license to display the preprint in perpetuity.

It is made available under a CC-BY-ND 4.0 International license .

151 response better than PD-L1 IHC $(P=.04)$ while $\mathrm{mIHC} / \mathrm{IF}$ failed to reach statistical significance

152 for improvement over PD-L1 IHC $(P=.06)$ (Supplementary Fig. 6).

153 Targeted somatic mutations: None of the targeted mutations were significantly better

154 than random chance at classifying responders (gAUC=0.50) (Fig. 3, Supplemental Table 8). A

155 single study $\underline{31}$ investigating alterations in DNA damage response genes as biomarker for

156 individuals with urothelial cancer, had the greatest observed sensitivity of 0.90 , but its specificity

157 was only 0.50 . Although only based on a single study $\underline{32}$ of 38 individuals with melanoma, using

158 wildtype for $B R C A 2$ as a biomarker resulted in a sensitivity of 0.71 and but only had a specificity

159 of 0.06 , indicating it resulted in too many false positives for predicting who is likely to respond

160 to treatment.

$161 \quad$ Microbiome: To our knowledge, the microbiome has been assessed for association with

162 response to anti-PD-1/PD-L1 treatment in only three studies, two of which were in patients with

163 melanoma. However, as described above, the microbiome was highly specific (specificity=0.90,

$16495 \%$ CI: 0.50-0.99), but was poorly sensitive (sensitivity=0.58, 95\% CI: 0.21-0.88). Similarly,

165 the specificity and sensitivity for the study ${ }^{33}$ in mixed cancer cases was 0.90 and 0.22 ,

166 respectively. In addition to the microbiome, multimodal biomarkers were the only other

167 biomarker that accurately captured significantly more non-responders than expected by random

168 chance (specificity $=0.60,95 \%$ CI: $0.54-0.70)$.

169 Discussion

170 ICIs targeting PD-1/PD-L1 have resulted in breakthrough treatments for a multitude of

171 cancers, and the impact this class of drugs has on cancer treatment cannot be overstated. Despite

172 these successes, only $24 \%(95 \% \mathrm{CI}=21 \%-28 \%)$ of patients respond to these treatments ${ }^{2}$. A

173 variety of different biomarkers have been considered; however, no consensus exists regarding 
174 which of these biomarkers is capable of or has potential to be clinically useful. This broad-based

175 meta-analysis addresses the unmet need of characterizing commonly considered biomarkers for

176 ICI treatment response in a variety of cancer types. To our knowledge, this is the most

177 comprehensive study of published biomarkers for ICI response performed to date, and builds off

178 of a recent meta-analysis performed by Lu et al. ${ }^{34}$. Here we extend that study in several ways by

179 expanding the number of studies from 46 to 95 , the number of patients from 8,135 to 18,978 ,

180 investigating whether the microbiome or immune mediated adverse events show evidence of

181 biomarker potential, and evaluating whether the AUCs of biomarker performance are statistically

182 different. We also implemented bivariate linear mixed models which has been shown to provide

183 more accurate estimates rather than estimating sensitivity and specificity separately, which can

184 yield misleading results ${ }^{34}$. Lastly, we use a summary receiver operating characteristic curve

185 (sROC) approach which addresses limitations for comparing binary tests across different studies

186 and statistical thresholds ${ }^{35}$.

187 We found that PD-L1 IHC, multimodal biomarkers, and mIHC/IF discriminate

188 responders significantly better than random assignment across all cancer types as well as specific

189 cancer types - melanoma and non-small-cell lung cancer (gAUC $>0.5$ ). TMB discriminated

190 responders better than random assignment across all cancer types and non-small-cell lung cancer

191 but not within melanoma patients. These findings are consistent with the results previously

192 published by $\mathrm{Lu}$ et $\mathrm{al}^{34}$. In addition, Lu et al. reported that $\mathrm{mIHC} / \mathrm{IF}$ and multimodal biomarkers

193 performed better than TMB and PD-L1 expression; however, here the performance of these

194 biomarkers was determined to be similar. Though the methodology is similar between these two

195 studies, some key differences may have led to discrepancies between these two studies. One of

196 the advantages to this study is the utilization of bootstrapping to test for statistical differences in 
medRxiv preprint doi: https://doi.org/10.1101/2020.11.25.20238865; this version posted November 29, 2020. The copyright holder for this preprint (which was not certified by peer review) is the author/funder, who has granted medRxiv a license to display the preprint in perpetuity.

It is made available under a CC-BY-ND 4.0 International license .

197 the biomarker accuracies. Similar to $\mathrm{Lu}$ et $\mathrm{al}^{34}$, we observed that the gAUC for mIHC/IF

198 (gAUC $=0.81,95 \%$ CI: 0.58-0.91) was higher than that of TMB (gAUC $=0.65,95 \%$ CI: 0.59 -

199 0.68) and PD-L1 IHC (gAUC=0.58, 95\% CI: 0.56-0.60); however, our approach did not find that

200 these biomarkers were significantly different $(P>.05)$. On the other hand, multimodal biomarkers

201 classified patients more accurately than PD-L1 IHC $(\Delta \mathrm{gAUC}=0.12, P=.04)$. Another notable

202 difference between the two studies is the definition of clinical response used. Here, in an effort to

203 maintain as much consistency in reported outcomes across studies, we only considered studies

204 that reported objective response rate (ORR), CB and PFS (6 months); whereas overall survival

205 and different PFS time points were also considered in Lu et al. ${ }^{34}$ While some clinical studies

206 have reported better efficacy of TMB than PD-L1 $\mathrm{IHC}^{36}$, other studies have found similar

207 performances between the two. ${ }^{34,37}$ We found that TMB demonstrated better performance

208 (gAUC $=0.65,95 \%$ CI: 0.59-0.68) than PD-L1 IHC (gAUC=0.58, 95\% CI: 0.56-0.60) $(P<.05)$.

209 Because clinical treatment decisions will be made on an individual patient level, we

210 investigated whether the weight of evidence supporting the use of a given biomarker differed

211 across cancer types. Cancer type is one of the sources of threshold and performance

212 heterogeneity of biomarkers between clinical studies. For example, Zhang et al. reported greater

213 treatment response in PD-L1 positive subgroups in melanoma, non-small-cell lung cancer and

214 renal cell carcinoma, but not in ovarian cancer, bladder cancer and multiple, combined cancer

215 types $^{2}$. Here, we found that, in melanoma, biomarkers mIHC/IF (gAUC $=0.82,95 \%$ CI: 0.53 -

$2160.93)$ and PD-L1 IHC (gAUC $=0.60,95 \%$ CI: 0.53-0.66) were not significantly different from

217 one another $(P>.05)$; whereas these were marginally significant across all cancer types $(P=.06)$

218 with gAUCs of 0.70 (95\% CI: 0.61-0.76) and 0.58 (95\% CI: 0.56-0.60) for mIHC/IF and PD-L1

219 expression, respectively. The mIHC/IF PD-L1 expression level had better predictive value than 
220 single PD-L1 expression IHC assays with a gAUC improvement of 0.23 with marginal

221 significance $(P=.06)$ across all cancer types. Tumor type, observing pathologist, assay type and

222 lack of broader assessment of tumor microenvironments assessment have all been reported to

223 negatively affect the efficacy of PD-L1 IHC $\mathrm{IH}^{34}$ TMB performance in melanoma varied greatly

$224(\mathrm{gAUC}=0.37,95 \%$ CI: 0.33-0.83), and was more homogeneous in non-small-cell lung cancer

$225(\mathrm{gAUC}=0.70,95 \% \mathrm{CI}: 0.60-0.74)$ and across all cancer types $(\mathrm{gAUC}=0.65,95 \%$ CI: $0.59-0.68)$.

226 Given these findings, there are likely other factors than just cancer type that contribute to

227 heterogeneity in performance and additional studies are needed to identify other factors that may

228 affect biomarker performance. However, meta-analyses provide relevant summaries of results

229 and aid in understanding relationships and heterogeneity in the context of multiple studies. ${ }^{38}$

230 Two of the more novel putative biomarkers of ICI treatment response included here are

231 AEs and the microbiome. The AEs biomarker is distinct from the others in that it is ascertained

232 after treatment has begun, limiting its potential use as a pre-treatment biomarker. However, if

233 determined to be effective it could still serve as a leading indicator of response, providing

234 opportunities to modify or enhance treatment. To our knowledge, AEs and response to ICIs have

235 only been explored in patients with urothelial cancer. ${ }^{23}$ Despite being significantly associated

236 with ORR, ${ }^{23}$ AEs were found to be the least sensitive for detecting responding individuals

237 (sensitivity=0.36). Defining this biomarker with a different criterion in different cancer types

238 may produce different results. To this point, the microbiome had a greater meta-analyzed

239 sensitivity estimate (sensitivity $=0.58,95 \% C I=0.21-0.88)$ for studies in melanoma patients than

240 the study conducted in multiple cancers (sensitivity=0.22). In addition, the microbiome was

241 highly specific for detecting non-responders in patients with melanoma (specificity=0.90, 95\%

242 CI: 0.50-0.99) and multiple cancers (specificity $=0.90)$, suggesting that it may have potential use 
medRxiv preprint doi: https://doi.org/10.1101/2020.11.25.20238865; this version posted November 29, 2020. The copyright holder for this preprint (which was not certified by peer review) is the author/funder, who has granted medRxiv a license to display the preprint in perpetuity.

It is made available under a CC-BY-ND 4.0 International license .

243 as a biomarker if used in combination with more sensitive biomarkers. The microbiome results

244 here also justify the investigation of this biomarker in other cancer types and potentially for use

245 with other classes of ICIs. The results of these constituent studies have not been prospectively

246 validated in an independent cohort. However, these meta-analyses provide what could be

247 considered an indication of the discriminatory potential for response to ICI treatment.

248 Multimodal and TMB outperformed PD-L1 IHC when all cancers were combined

$249(P<.05)$, with marginal improvements also seen for TMB and the microbiome over PD-L1 IHC

$250(P<.10)$. mIHC/IF, PD-L1 IHC and multimodal biomarkers adequately captured responders and

251 non-responders in patients with melanoma, non-small-cell lung cancer and across combined

252 cancer types better than random chance $(P<.05)$. Although TMB discriminated responders and

253 non-responders similar to other biomarkers for patients with non-small cell lung cancer and

254 when cancers were combined, TMB for patients with melanoma produced mixed results.

255 Overall, biomarker performance greatly depends on cancer type and studies vary widely based

256 on their methods; however, several biomarkers show promise for predicting treatment response

257 to ICIs and additional standardization will needed to maximize their clinical utility.

\section{Methods}

259 Literature Search and Inclusion Criteria:

260 PubMed and Google Scholar were used to search for peer-reviewed studies focused on

261 anti-PD-1/anti-PD-L1 therapies and biomarkers. Keywords used to search for studies included:

262 "anti-PD-1/anti-PD-L1 therapies and tumor mutational burden", "anti-PD-1/anti-PD-L1 therapies

263 and adverse events", "anti-PD-1/anti-PD-L1 therapies and biomarkers" and "biomarkers for

264 immune check point inhibitors". Studies were selected based on accessibility and availability of

265 summary level or patient level data based on clinical outcomes and predictive biomarkers. 
medRxiv preprint doi: https://doi.org/10.1101/2020.11.25.20238865; this version posted November 29, 2020. The copyright holder for this preprint (which was not certified by peer review) is the author/funder, who has granted medRxiv a license to display the preprint in perpetuity.

It is made available under a CC-BY-ND 4.0 International license .

$\underline{\text { Data }}$

For each study, the title, publication year, treatment, type of cancer, biomarker and

268 clinical outcome details were documented. CB, ORR and PFS were considered as clinical

269 outcomes. The clinical outcomes and biomarker thresholds were accepted as defined in each

270 study. The following metrics for biomarker performance were calculated: sensitivity, specificity,

271 balanced accuracy (BA), positive predictive value (PPV), negative predictive value (NPV), false

272 omission rate (FOR), false negative rate (FNR), and false discovery rate (FDR). Each of these

273 metrics can be calculated from a $2 \times 2$ contingency table where counts of individuals meeting the

274 criterion for being positive or negative for the biomarker under consideration and being positive

275 or negative for the clinical outcome (Supplemental Table 1). Only studies that provided either

276 individual counts for each cell in the $2 \times 2$ table or the necessary individual level information to

277 complete the $2 \times 2$ table were included. Studies that did not propose a threshold or cutoff value for

278 the biomarker were excluded unless participant level data was available from which a $2 \times 2$ table

279 could be developed.

Patient and Public Involvement: Patients were not involved in performing this research.

281 All patient data was reported separately in the relevant peer reviewed publications which can be

282 found in Supplemental Table 2.

283 Biomarkers: Across all included studies, the following biomarkers were investigated

284 (Supplementary Table 3). Some studies evaluated multiple biomarker thresholds and only the

285 results with the threshold resulting in the highest reported balanced accuracy were included for

286 analysis. Biomarkers with less than three reported studies or a total combined patient count $=<$

287500 were combined to form a group referred to as "other" biomarkers (Supplemental Table 4).

288 The most frequently observed biomarkers are described below: 
medRxiv preprint doi: https://doi.org/10.1101/2020.11.25.20238865; this version posted November 29, 2020. The copyright holder for this preprint (which was not certified by peer review) is the author/funder, who has granted medRxiv a license to display the preprint in perpetuity. It is made available under a CC-BY-ND 4.0 International license .

PD-L1 protein expression: $\mathrm{PD}-\mathrm{L} 1$ protein expression measured on tumor cells, immune cells or both, were included. For each study, the investigators selected an expression threshold to

291 compare observed clinical responses. Patients with PD-L1 expression greater than the threshold

292 were expected to be more likely to respond to treatment. PD-L1 expression was further divided 293 into assay type subsets of IHC and mIHC/IF.

294 Tumor mutational burden $(T M B)$ : TMB refers to the number of somatic DNA mutations

295 across the tumor genome. Since the early studies of TMB, many variations of this biomarker

296 have been studied. Tumor mutational burden has been quantified based on non-synonymous

297 single nucleotide variants ${ }^{32,39}$, frameshift mutations ${ }^{40}$ and circulating tumor DNA ${ }^{41}$. Studies

298 calculating TMB from whole exome or whole genome sequencing were included, as well.

299 Median TMB was a commonly reported threshold for assessing response to ICIs, although some

300 studies investigated alternative thresholds. The TMB threshold defined by the authors of each

301 study was accepted for the analysis here, with the exception of Hugo et al. ${ }^{32}$, which did not report

302 a threshold and the median TMB was used. For all studies, TMB was evaluated to determine if

303 being above the threshold was indicative of increased likelihood of response to treatment.

$304 \quad$ Targeted somatic mutations: Many studies have investigated whether somatic mutations

305 in specific genes could serve as biomarkers for response to ICIs. We focused on several

306 commonly reported mutations in the following genes: B-Raf proto-oncogene, serine/threonine

307 kinase $(B R A F)^{5,42-47}$, progesterone receptor $(P R)^{9,48}$, estrogen receptor alpha $(\mathrm{ERa})^{9,48}$, KRAS

308 proto-oncogene, GTPase $(K R A S)^{32,44,46}, K R A S$ and $N R A S$ genes (KRAS/NRAS) $)^{45,49}$ and tumor

309 protein $\mathrm{p} 53$. Some of these mutations are more common in certain cancers. Therefore, we

310 presented this information in two ways: (i) individual gene performance across all reported 
311 cancers, and (ii) we meta-analyzed each of these genes to provide an overall assessment for how

312 well individual targeted somatic mutations discriminate patient response to ICIs.

314 prior to treatment initiation, adverse events of special interest (AEs) were observed after the

315 administration of ICIs, but prior to the determination of a clinical response. AEs included a

316 variety of events including autoimmune events, rash, diarrhea, and others ${ }^{23}$. These data were

317 previously reported in Maher et al. which combined data from five trials submitted to the US

318 Food and Drug Administration (FDA) ${ }^{23}$ and we previously reported the discriminatory potential

319 for these biomarkers ${ }^{50}$. AEs were evaluated to determine if their occurrence was indicative of

320 increased likelihood of response to treatment.

$321 \quad$ Gene expression profiles $(G E P)$ : GEPs classify responders based on arrays of

322 inflammatory-, immune checkpoint and onco-genes. The studies focused on expression of

323 indoleamine 2,3-dioxygenase (IDO) and FOXP3 as well as angiogenesis gene signature (Angio),

324 T-cell effector gene signature (Teff) and innate anti-PD-1 resistance gene signature (IPRES).

325 Significant associations between high expression of $F O X P 3$ and $I D O$ with clinical efficacy were

326 reported $^{22,32,40,43}$. Presence of Angio and Teff signatures along with absence of IPRES signature

327 were also associated with clinical efficacy $22,32,40$.

328 Microbiome: Individuals with gut and oral commensal microbiomes that promote anti-

329 tumor immunity have been shown to benefit more from ICI treatments than others ${ }^{51,52}$.

330 Conversely, down-regulation of these microbiomes by antibiotics has been linked to worse

331 treatment responses ${ }^{33}$. Furthermore, pre-treatment microbiome profiles have been reported to

332 discriminate responders and non-responders ${ }^{51}$. 
medRxiv preprint doi: https://doi.org/10.1101/2020.11.25.20238865; this version posted November 29, 2020. The copyright holder for this preprint (which was not certified by peer review) is the author/funder, who has granted medRxiv a license to display the preprint in perpetuity.

It is made available under a CC-BY-ND 4.0 International license .

Multimodal biomarkers: All of the biomarkers described above capture distinct

334 information about the tumor microenvironment (e.g. TMB, PD-L1 IHC) and the host (e.g. GEP,

335 Microbiome). Some studies have combined TMB with PD-L1 and GEP and PD-1 IHC with PD-

336 L1 IHC for a comprehensive assessment of the tumor and clinical efficacy.

337 Clinical responses: Either ORR, CB or PFS were used to represent clinical response to

338 treatment. If ORR was not available, in order of preference, CB and six-months PFS were used.

339 These responses were determined using response evaluation criteria in solid tumors (RECIST),

340 immune-related response criteria (irRC), or modified response evaluation criteria in solid tumors

341 (mRECIST) $)^{53,54}$ by investigator assessment or independent review. If a response was evaluated

342 using multiple tumor criteria or by multiple assessors, the data was averaged to the nearest

343 integer.

344 Statistical Analysis

$345 \quad$ Meta-analysis: A PRISMA checklist detailing quality control metrics for reporting meta-

346 analyses used in this study are presented in the Supplemental Material. Biomarker performance

347 metrics (Supplementary Table 1) were calculated for each study and various groups were meta-

348 analyzed for comparison using the R packages, mada $\underline{55}$ and meta4diag $\underline{56}$. Meta-analyses were

349 conducted on data subsets to determine (i) discriminatory potential for each biomarker across

350 multiple cancer types (Supplemental Table 4), and (ii) discriminatory potential for each

351 biomarker for each cancer type. Binary test outcomes, such as sensitivity and specificity, rely on

352 a threshold for determining the optimal test performance. However, this threshold often creates a

353 tradeoff between certain values. In addition, simply averaging values across studies with

354 different thresholds can confound results ${ }^{57}$. To address this, we implemented the sROC

355 approach $^{35,55}$. Bivariate analyses were performed using a linear mixed model with random effects 
medRxiv preprint doi: https://doi.org/10.1101/2020.11.25.20238865; this version posted November 29, 2020. The copyright holder for this preprint (which was not certified by peer review) is the author/funder, who has granted medRxiv a license to display the preprint in perpetuity.

It is made available under a CC-BY-ND 4.0 International license.

356 and evaluated specificity, positive predictive value and negative predictive value with false

357 negative rate, false omission rate and false discovery rate, respectively. A minimum size of three

358 studies was required in order to perform each meta-analysis. Both partial AUCs (pAUC) and

359 global AUCs (gAUCs) were calculated. While the pAUC estimates the discriminatory ability of

360 the observed data, gAUC estimates are calculated from the extrapolated bivariate models. The

361 confidence intervals for both AUC estimates were estimated based on a bootstrapped sample of

36210,000 iterations $^{58}$.

363 Bootstrap hypothesis testing: Biomarkers were compared pairwise to determine if the

364 observed gAUC values were significantly different $(P<.05)$. Null distributions were generated

365 for the difference in the gAUC estimates between each pairwise biomarker by calculating the

366 difference in the gAUC values assigned to a random mix of the studies focused on biomarkers of

367 interest. Each distribution consisted of 10,000 such values, and the probability of differences

368 observed between the biomarker estimates were calculated as the number of observed gAUC

369 values greater than the gAUC from the null distribution, divided by 10,000. 
370 Figures
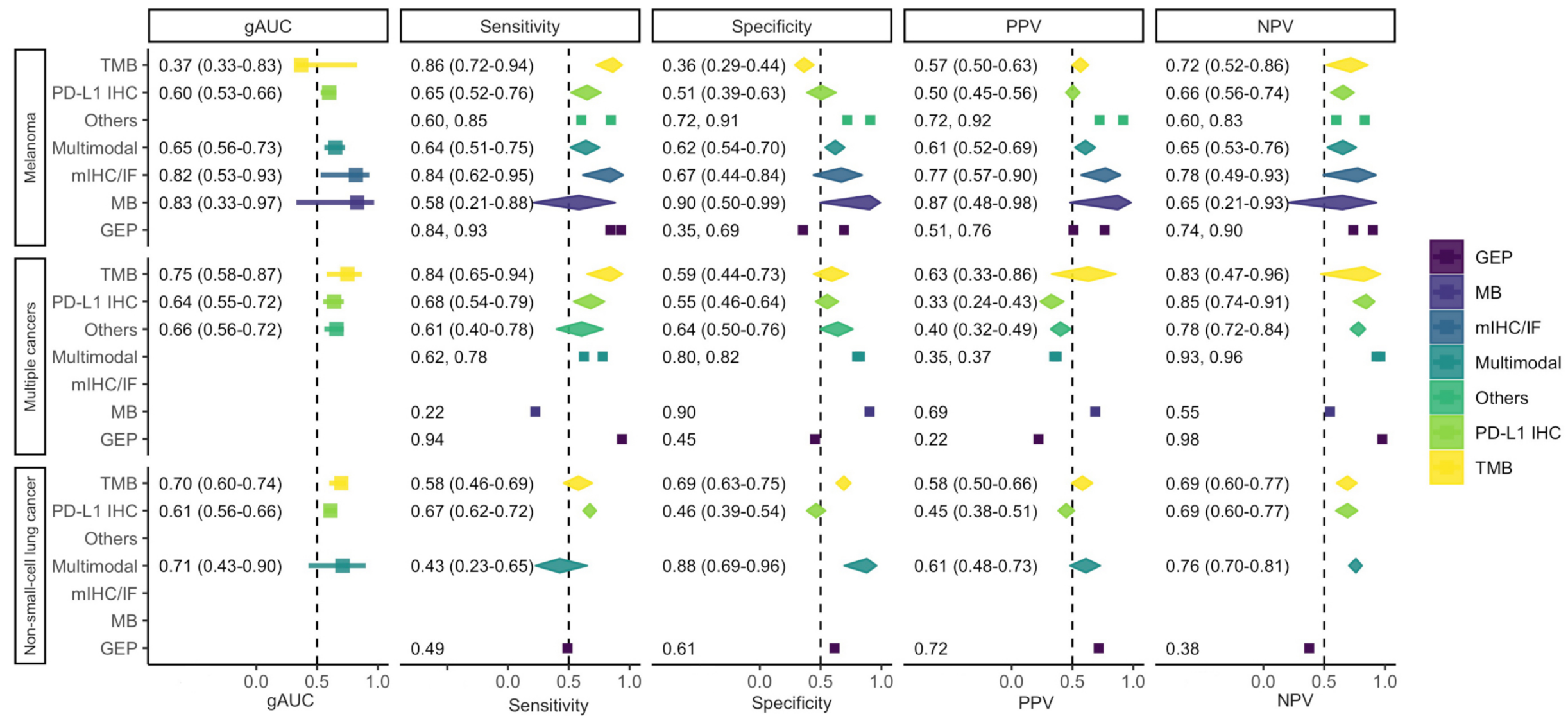

Fig 1. Meta-analyzed estimates for biomarkers within the three most frequently reported cancer groups.

The sensitivity, specificity, positive predictive value (PPV) and negative predictive value (NPV) were meta-analyzed with false positive rate (FPR), false negative rate (FNR), false omission rate (FOR) and false discovery rate (FDR) using the linear regression approach with mixed effects implemented in R mada package ${ }^{55}$. The value for extrapolated area under the curve (gAUC) was calculated from sROC curves fitted for each biomarker within each cancer type using the Rutter-Gastonis method. The bars on gAUC facets represent $95 \%$ bootstrapped confidence intervals $(95 \% \mathrm{CI})$. 


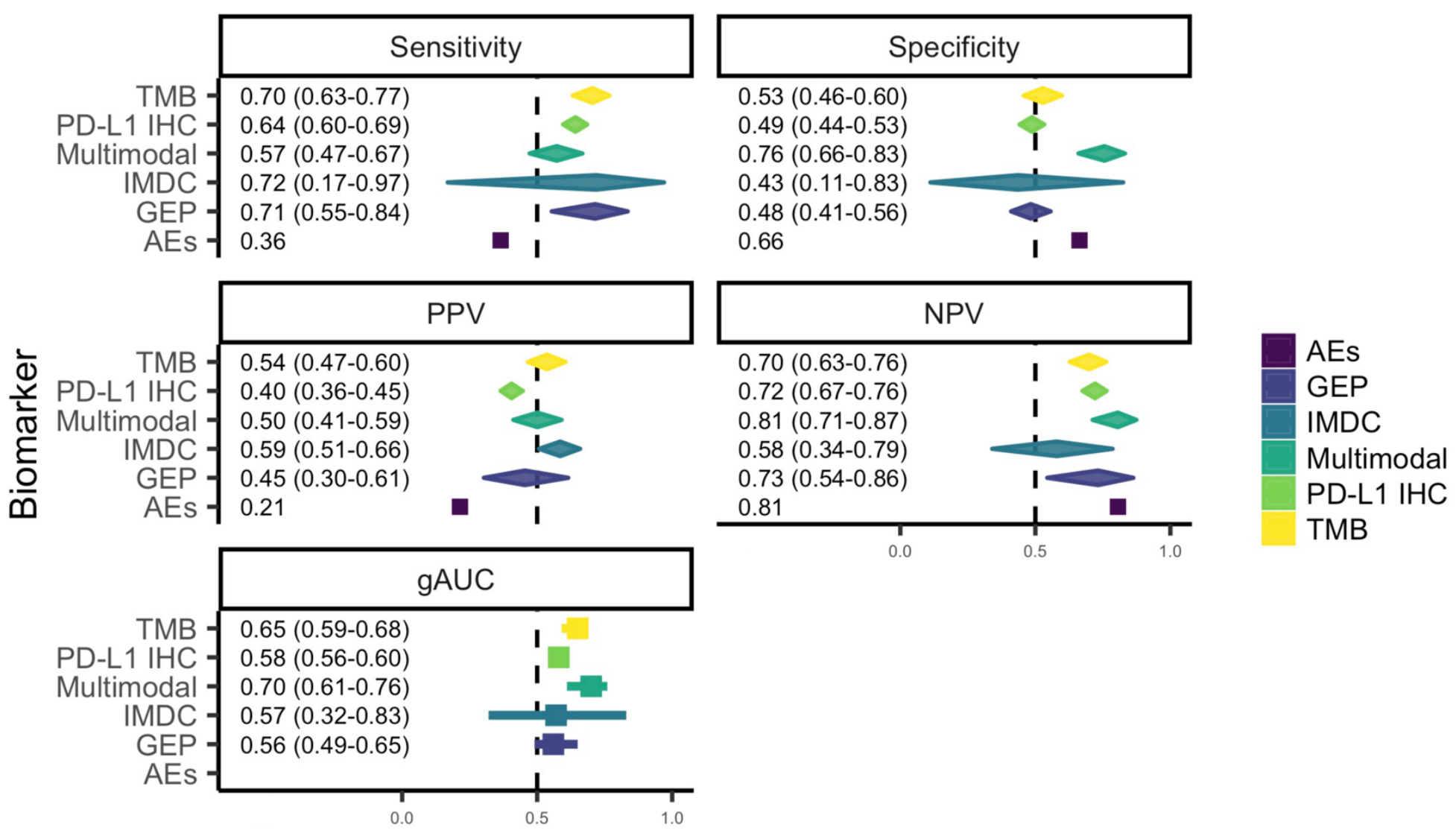

Fig 2. Meta-analyzed estimates of biomarkers with across cancers with pooled sample sizes greater than 500

381 The meta-analyzed sensitivity, specificity, positive predictive value (PPV), negative predictive value (NPV) and extrapolated area under the curve (gAUC) across cancers with a pooled sample size $>500$. The sensitivity, specificity, PPV and NPV were meta-

383 analyzed with false positive rate (FPR), false negative rate (FNR), false omission rate (FOR) and false discovery rate (FDR) using the linear regression approach with mixed effects implemented in R mada package ${ }^{55}$. The values for gAUC was calculated from sROC curves fitted for each biomarker within each cancer type using the Rutter-Gastonis method. The bars on gAUC facets represent $95 \%$ 

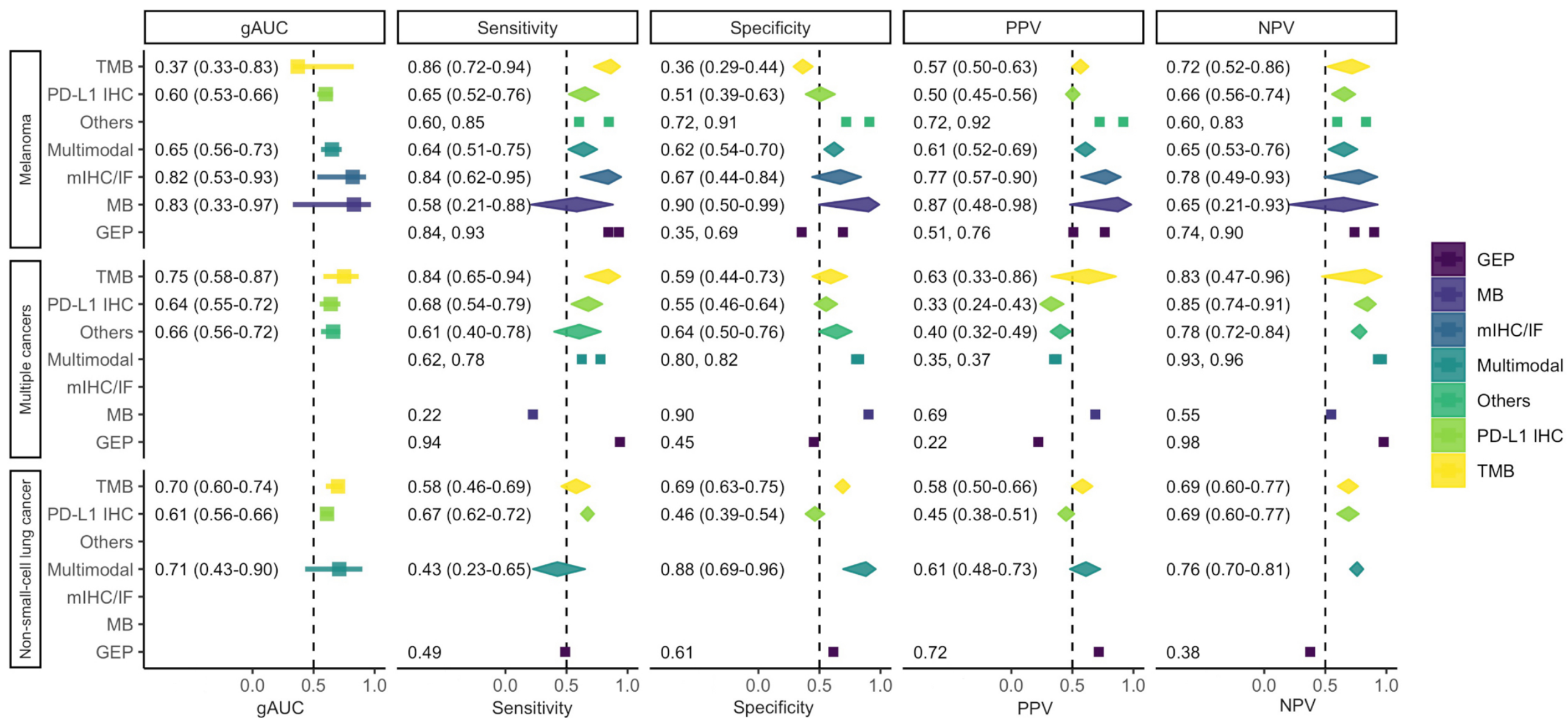

389 Fig 3. Meta-analyzed estimates for targeted somatic mutations

390 Meta-analyzed sensitivity, specificity, positive predictive value (PPV), negative predictive value (NPV) and extrapolated area under the curve (gAUC) values. The sensitivity, specificity, PPV and NPV were meta-analyzed with false positive rate (FPR), false negative rate (FNR), false omission rate (FOR) and false discovery rate (FDR) using the linear regression approach with mixed effects implemented in R mada package ${ }^{55}$. The values for gAUC was calculated from sROC curves fitted for each biomarker within each 
CI).

\section{Tables}

Table 1. Meta-analyzed estimates of each biomarker for most commonly reported cancer categories

\begin{tabular}{|c|c|c|c|c|c|c|c|c|}
\hline Cancer & Biomarker & $\begin{array}{c}\text { Studies } \\
(\mathrm{N})\end{array}$ & $\begin{array}{c}\text { Individuals } \\
(\mathrm{N})\end{array}$ & $\begin{array}{c}\text { gAUC } \\
(95 \% \mathrm{CI})\end{array}$ & $\begin{array}{c}\text { Sensitivity } \\
(95 \% \mathrm{CI})\end{array}$ & $\begin{array}{c}\text { Specificity } \\
(95 \% \mathrm{CI})\end{array}$ & $\begin{array}{c}\text { PPV }^{2} \\
(95 \% \mathrm{CI})\end{array}$ & $\begin{array}{c}\mathrm{NPV}^{3} \\
(95 \% \mathrm{CI})\end{array}$ \\
\hline \multirow{4}{*}{ Melanoma } & MB & 2 & 128 & $0.83(0.33-0.97)$ & $0.58(0.21-0.88)$ & $0.90(0.50-0.99)$ & $0.87(0.48-0.98)$ & $0.65(0.2-0.93)$ \\
\cline { 2 - 8 } & mIHC/IF & 2 & 157 & $0.82(0.53-0.93)$ & $0.84(0.62-0.95)$ & $0.67(0.44-0.84)$ & $0.77(0.57-0.90)$ & $0.78(0.49-0.93)$ \\
\cline { 2 - 8 } & Multimodal & 2 & 231 & $0.65(0.56-0.73)$ & $0.64(0.51-0.75)$ & $0.62(0.54-0.70)$ & $0.61(0.52-0.69)$ & $0.65(0.53-0.76)$ \\
\cline { 2 - 8 } & PD-L1 IHC & 14 & 2313 & $0.6(0.53-0.66)$ & $0.65(0.52-0.76)$ & $0.51(0.39-0.63)$ & $0.50(0.45-0.56)$ & $0.66(0.56-0.74)$ \\
\cline { 2 - 9 } & TMB & 4 & 227 & $0.37(0.33-0.83)$ & $0.86(0.72-0.94)$ & $0.36(0.29-0.44)$ & $0.57(0.50-0.63)$ & $0.72(0.52-0.86)$ \\
\hline \multirow{5}{*}{\begin{tabular}{c} 
Multiple cancers \\
\cline { 2 - 9 }
\end{tabular}} & Others ${ }^{4}$ & 2 & 107 & $0.66(0.56-0.72)$ & $0.61(0.40-0.78)$ & $0.64(0.50-0.76)$ & $0.40(0.32-0.49)$ & $0.78(0.72-0.84)$ \\
\cline { 2 - 9 } & PD-L1 IHC & 6 & 693 & $0.64(0.55-0.72)$ & $0.68(0.54-0.79)$ & $0.55(0.46-0.64)$ & $0.33(0.24-0.43)$ & $0.85(0.74-0.91)$ \\
\cline { 2 - 9 } & TMB & 3 & 231 & $0.75(0.58-0.87)$ & $0.84(0.65-0.94)$ & $0.59(0.44-0.73)$ & $0.63(0.33-0.86)$ & $0.83(0.47-0.96)$ \\
\hline \multirow{4}{*}{$\begin{array}{c}\text { Non-small-cell lung } \\
\text { cancer }\end{array}$} & Multimodal & 3 & 304 & $0.71(0.43-0.9)$ & $0.43(0.23-0.65)$ & $0.88(0.69-0.96)$ & $0.61(0.48-0.73)$ & $0.76(0.70-0.81)$ \\
\cline { 2 - 9 } & PD-L1 IHC & 22 & 5623 & $0.61(0.56-0.66)$ & $0.67(0.62-0.72)$ & $0.46(0.39-0.54)$ & $0.45(0.38-0.51)$ & $0.69(0.60-0.77)$ \\
\cline { 2 - 9 } & TMB & 9 & 1285 & $0.7(0.6-0.74)$ & $0.58(0.46-0.69)$ & $0.69(0.63-0.75)$ & $0.58(0.50-0.66)$ & $0.69(0.60-0.77)$ \\
\hline
\end{tabular}


403 Table 2. Meta-analyzed estimates of biomarkers across all studies and cancer types

\begin{tabular}{|c|c|c|c|c|c|c|c|}
\hline Biomarker & $\begin{array}{c}\text { Studies } \\
(\mathrm{N})\end{array}$ & $\begin{array}{c}\text { Individuals } \\
(\mathrm{N})\end{array}$ & $\begin{array}{c}\text { gAUC } \\
(95 \% \mathrm{CI})\end{array}$ & $\begin{array}{c}\text { Sensitivity } \\
(95 \% \mathrm{CI})\end{array}$ & $\begin{array}{c}\text { Specificity } \\
(95 \% \mathrm{CI})\end{array}$ & $\begin{array}{c}\mathrm{PPV}^{2} \\
(95 \% \mathrm{CI})\end{array}$ & $\begin{array}{c}\text { NPV } \\
(95 \% \mathrm{CI})\end{array}$ \\
\hline AEs & 1 & 1747 & & 0.36 & 0.66 & 0.21 & 0.81 \\
\hline GEP & 5 & 783 & $0.56(0.49-0.65)$ & $0.71(0.55-0.84)$ & $0.48(0.41-0.56)$ & $0.45(0.30-0.61)$ & $0.73(0.54-0.86)$ \\
\hline IMDC & 2 & 547 & $0.57(0.32-0.83)$ & $0.72(0.17-0.97)$ & $0.43(0.11-0.83)$ & $0.59(0.51-0.66)$ & $0.58(0.34-0.79)$ \\
\hline MB & 3 & 228 & $0.81(0.38-0.95)$ & $0.48(0.19-0.78)$ & $0.90(0.67-0.98)$ & $0.79(0.53-0.92)$ & $0.62(0.30-0.86)$ \\
\hline mIHC/IF & 3 & 177 & $0.81(0.58-0.91)$ & $0.85(0.68-0.94)$ & $0.66(0.49-0.80)$ & $0.78(0.63-0.89)$ & $0.76(0.56-0.89)$ \\
\hline Multimodal & 5 & 559 & $0.7(0.61-0.76)$ & $0.57(0.47-0.67)$ & $0.76(0.66-0.83)$ & $0.50(0.41-0.59)$ & $0.81(0.71-0.87)$ \\
\hline Others ${ }^{4}$ & 10 & 1001 & $0.67(0.58-0.71)$ & $0.60(0.50-0.69)$ & $0.69(0.56-0.79)$ & $0.46(0.37-0.55)$ & $0.81(0.72-0.87)$ \\
\hline PDL1-IHC & 76 & 13909 & $0.58(0.56-0.6)$ & $0.64(0.60-0.69)$ & $0.49(0.44-0.53)$ & $0.40(0.36-0.45)$ & $0.72(0.67-0.76)$ \\
\hline TMB & 15 & 1814 & $0.65(0.59-0.68)$ & $0.70(0.63-0.77)$ & $0.53(0.46-0.60)$ & $0.54(0.47-0.60)$ & $0.70(0.63-0.76)$ \\
\hline
\end{tabular}

$404{ }^{1}$ global area under the receiver operating characteristic curve; ${ }^{2}$ positive predictive value; ${ }^{3}$ negative predictive value; ${ }^{4}$ listed in 405 Supplemental Table 3. 
medRxiv preprint doi: https://doi.org/10.1101/2020.11.25.20238865; this version posted November 29, 2020. The copyright holder for this preprint (which was not certified by peer review) is the author/funder, who has granted medRxiv a license to display the preprint in perpetuity.

It is made available under a CC-BY-ND 4.0 International license .

Declarations

409 Data Sharing Statement: All available data is provided in the Supplementary Material and through the publications referenced in the Supplementary Material.

411 Funding: D.M.R. and A.M. were supported in part by the Clinical and Translational Science

412 Collaborative of Cleveland, (KL2TR002547) from the National Center for Advancing

413 Translational Sciences (NCATS) component of the NIH.

414 Competing Interests: D.M.R. has stock and other ownership interests in Interpares Biomedicine.

415 He has served in a consultant and advisory role for Pharmazam and Clariifi. He has received

416 research funding from Novo Nordisk and has intellectual property related to the detection of liver

417 cancer. H.L.M. has stock and other ownership interests in Cancer Genetics, Interpares

418 Biomedicine, Clariifi, and serves as a consultant or advisory role for Gentris, Cancer Genetics,

419 Saladax Biomedical, National Institutes of Health/National Cancer Institute, Admera Health,

420 eviCore healthcare, Pharmazam, VieCure.

421 Disclaimer: The funders had no role in study design, data collection and analysis, interpretation, 422 decision to publish, or preparation of the manuscript; or any aspect of the study.

423 Contributions: A.M. performed analyses and wrote the manuscript. K.S., performed analyses and 424 reviewed the manuscript. S.K. and H.L.M. reviewed the manuscript and provided feedback.

425 D.M.R. designed and supervised the study, wrote and reviewed the manuscript.

427 References

428 1. Hao, C. et al. Efficacy and safety of anti-PD-1 and anti-PD-1 combined with anti-CTLA-4

429 immunotherapy to advanced melanoma: A systematic review and meta-analysis of

$430 \quad$ randomized controlled trials. Medicine (United States) vol. 96 (2017).

431 2. Zhang, T. et al. The efficacy and safety of anti-PD-1/PD-L1 antibodies for treatment of

432 advanced or refractory cancers: A meta-analysis. Oncotarget 7, 73068-73079 (2016).

433 3. Rosenberg, J. E. et al. Atezolizumab in patients with locally advanced and metastatic

434 urothelial carcinoma who have progressed following treatment with platinum-based

435 chemotherapy: A single-arm, multicentre, phase 2 trial. The Lancet 387, 1909-1920 (2016). 
medRxiv preprint doi: https://doi.org/10.1101/2020.11.25.20238865; this version posted November 29, 2020. The copyright holder for this preprint (which was not certified by peer review) is the author/funder, who has granted medRxiv a license to display the preprint in perpetuity.

It is made available under a CC-BY-ND 4.0 International license .

436 4. Kato, K. et al. Nivolumab versus chemotherapy in patients with advanced oesophageal squamous cell carcinoma refractory or intolerant to previous chemotherapy (ATTRACTION-3): a multicentre, randomised, open-label, phase 3 trial. Lancet Oncol. 20,

5. Weber, J. S. et al. Nivolumab versus chemotherapy in patients with advanced melanoma who progressed after anti-CTLA-4 treatment (CheckMate 037): A randomised, controlled, open-

6. Powles, T. et al. Atezolizumab versus chemotherapy in patients with platinum-treated locally advanced or metastatic urothelial carcinoma (IMvigor211): a multicentre, open-label, phase 3 randomised controlled trial. The Lancet 391, 748-757 (2018).

7. Rittmeyer, A. et al. Atezolizumab versus docetaxel in patients with previously treated nonsmall-cell lung cancer (OAK): a phase 3, open-label, multicentre randomised controlled trial.

$$
\text { The Lancet 389, 255-265 (2017). }
$$

449 8. Taube, J. M. et al. Association of PD-1, PD-1 ligands, and other features of the tumor immune microenvironment with response to anti-PD-1 therapy. Clin. Cancer Res. 20, 5064-

9. Dirix, L. Y. et al. Avelumab, an anti-PD-L1 antibody, in patients with locally advanced or metastatic breast cancer: A phase 1b JAVELIN solid tumor study. Breast Cancer Res. Treat. 167, 671-686 (2018).

10. Kefford, R. et al. Clinical efficacy and correlation with tumor PD-L1 expression in patients (pts) with melanoma (MEL) treated with the anti-PD-1 monoclonal antibody MK-3475. J. Clin. Oncol. 32, 3005-3005 (2014). 
medRxiv preprint doi: https://doi.org/10.1101/2020.11.25.20238865; this version posted November 29, 2020. The copyright holder for this preprint (which was not certified by peer review) is the author/funder, who has granted medRxiv a license to display the preprint in perpetuity.

It is made available under a CC-BY-ND 4.0 International license .

458 11. Passiglia, F. et al. PD-L1 expression as predictive biomarker in patients with NSCLC: A

459 pooled analysis. Oncotarget 7, 19738-19747 (2016).

460 12. Goodman, A. M. et al. Tumor mutational burden as an independent predictor of response to

461 immunotherapy in diverse cancers. Mol. Cancer Ther. 16, 2598-2608 (2017).

462 13. Ready, N. et al. First-Line Nivolumab Plus Ipilimumab in Advanced Non-Small-Cell Lung

463 Cancer (CheckMate 568): Outcomes by Programmed Death Ligand 1 and Tumor Mutational

464 Burden as Biomarkers. J. Clin. Oncol. Off. J. Am. Soc. Clin. Oncol. 37, 992-1000 (2019).

465 14. Gandara, D. R. et al. Blood-based tumor mutational burden as a predictor of clinical benefit

466 in non-small-cell lung cancer patients treated with atezolizumab. Nat. Med. 24, 1441-1448

467 (2018).

468 15. Hellmann, M. D. et al. Tumor Mutational Burden and Efficacy of Nivolumab Monotherapy

469 and in Combination with Ipilimumab in Small-Cell Lung Cancer. Cancer Cell 33, 853-

$470 \quad$ 861.e4 (2018).

471 16. Marabelle, A. et al. Association of tumour mutational burden with outcomes in patients with

472 advanced solid tumours treated with pembrolizumab: prospective biomarker analysis of the

473 multicohort, open-label, phase 2 KEYNOTE-158 study. Lancet Oncol. 21, 1353-1365

$474 \quad$ (2020).

475 17. Rizvi, H. et al. Molecular determinants of response to anti-programmed cell death (PD)-1

476 and anti-programmed death-ligand 1 (PD-L1) blockade in patients with non-small-cell lung

477 cancer profiled with targeted next-generation sequencing. J. Clin. Oncol. 36, 633-641

$478 \quad$ (2018).

479 18. Hellmann, M. D. et al. Genomic Features of Response to Combination Immunotherapy in

480 Patients with Advanced Non-Small-Cell Lung Cancer. Cancer Cell 33, 843-852.e4 (2018). 
medRxiv preprint doi: https://doi.org/10.1101/2020.11.25.20238865; this version posted November 29, 2020. The copyright holder for this preprint (which was not certified by peer review) is the author/funder, who has granted medRxiv a license to display the preprint in perpetuity.

It is made available under a CC-BY-ND 4.0 International license .

481 19. Havel, J. J., Chowell, D. \& Chan, T. A. The evolving landscape of biomarkers for checkpoint

482 inhibitor immunotherapy. Nature Reviews Cancer vol. 19 133-150 (2019).

483 20. Borghaei, H. et al. Nivolumab versus docetaxel in advanced nonsquamous non-small-cell

484 lung cancer. N. Engl. J. Med. 373, 1627-1639 (2015).

485 21. Forde, P. M. et al. Neoadjuvant PD-1 blockade in resectable lung cancer. N. Engl. J. Med.

$486 \quad 378,1976-1986(2018)$.

487 22. Socinski, M. A. et al. Atezolizumab for first-line treatment of metastatic nonsquamous

$488 \quad$ NSCLC. N. Engl. J. Med. 378, 2288-2301 (2018).

489 23. Maher, V. E. et al. Analysis of the Association Between Adverse Events and Outcome in

490 Patients Receiving a Programmed Death Protein 1 or Programmed Death Ligand 1 Antibody.

491 J. Clin. Oncol. Off. J. Am. Soc. Clin. Oncol. 37, 2730-2737 (2019).

492 24. Bellmunt, J. et al. Pembrolizumab as Second-Line Therapy for Advanced Urothelial

493 Carcinoma. N. Engl. J. Med. 376, 1015-1026 (2017).

494 25. Massard, C. et al. Safety and Efficacy of Durvalumab (MEDI4736), an Anti-Programmed

495 Cell Death Ligand-1 Immune Checkpoint Inhibitor, in Patients With Advanced Urothelial

496 Bladder Cancer. J. Clin. Oncol. Off. J. Am. Soc. Clin. Oncol. 34, 3119-25 (2016).

497 26. Kambayashi, Y., Fujimura, T., Hidaka, T. \& Aiba, S. Biomarkers for Predicting Efficacies of

498 Anti-PD1 Antibodies. Front. Med. 6, 174 (2019).

499 27. Topalian, S. L., Taube, J. M., Anders, R. A. \& Pardoll, D. M. Mechanism-driven biomarkers

500 to guide immune checkpoint blockade in cancer therapy. Nature Reviews Cancer vol. 16

$501 \quad 275-287(2016)$

502 28. Janjigian, Y. Y. et al. 【CheckMate-032試験】二次治療以降の切除不能胃癌に対する

503 ニボルマブェイピリムマブ療法の第I/II相試験. J. Clin. Oncol. 36, 2836-2844 (2018). 
medRxiv preprint doi: https://doi.org/10.1101/2020.11.25.20238865; this version posted November 29, 2020. The copyright holder for this preprint (which was not certified by peer review) is the author/funder, who has granted medRxiv a license to display the preprint in perpetuity.

It is made available under a CC-BY-ND 4.0 International license .

504

505

506

507

508

509

510

511

512

513

514

515

516

517

518

519

520

521

522

523

524

525

29. Tykodi, S. S. et al. First-line pembrolizumab (pembro) monotherapy in advanced clear cell renal cell carcinoma (ccRCC): Updated results for KEYNOTE-427 cohort A. J. Clin. Oncol. 37, 4570-4570 (2019).

30. Motzer, R. J. et al. Nivolumab plus Ipilimumab versus Sunitinib in advanced renal-cell carcinoma. N. Engl. J. Med. 378, 1277-1290 (2018).

31. Teo, M. Y. et al. Alterations in DNA damage response and repair genes as potential marker of clinical benefit from PD-1/PD-L1 blockade in advanced urothelial cancers. J. Clin. Oncol. 36, 1685-1694 (2018).

32. Hugo, W. et al. Genomic and Transcriptomic Features of Response to Anti-PD-1 Therapy in Metastatic Melanoma. Cell 165, 35-44 (2016).

33. Routy, B. et al. Gut microbiome influences efficacy of PD-1-based immunotherapy against epithelial tumors. Science 359, 91-97 (2018).

34. Lu, S. et al. Comparison of Biomarker Modalities for Predicting Response to PD-1/PD-L1 Checkpoint Blockade: A Systematic Review and Meta-analysis. JAMA Oncology vol. 5 1195-1204 (2019).

35. Holling, H., Böhning, W. \& Böhning, D. Meta-analysis of diagnostic studies based upon SROC-curves: A mixed model approach using the Lehmann family. Stat. Model. 12, 347375 (2012).

36. Boumber, Y. Tumor mutational burden (TMB) as a biomarker of response to immunotherapy in small cell lung cancer. Journal of Thoracic Disease vol. 10 4689-4693 (2018).

37. Aggen, D. H. \& Drake, C. G. Biomarkers for immunotherapy in bladder cancer: A moving target. Journal for ImmunoTherapy of Cancer vol. 594 (2017). 
medRxiv preprint doi: https://doi.org/10.1101/2020.11.25.20238865; this version posted November 29, 2020. The copyright holder for this preprint (which was not certified by peer review) is the author/funder, who has granted medRxiv a license to display the preprint in perpetuity.

It is made available under a CC-BY-ND 4.0 International license .

526 38. Greco, T., Zangrillo, A., Biondi-Zoccai, G. \& Landoni, G. Meta-analysis: pitfalls and hints.

$527 \quad$ Heart Lung Vessels 5, 219-25 (2013).

528 39. Rizvi, N. A. et al. Mutational landscape determines sensitivity to PD-1 blockade in non-

529 small cell lung cancer. Science 348, 124-128 (2015).

530 40. McDermott, D. F. et al. Clinical activity and molecular correlates of response to

531 atezolizumab alone or in combination with bevacizumab versus sunitinib in renal cell

532 carcinoma. Nat. Med. 24, 749-757 (2018).

533 41. Khagi, Y. et al. Hypermutated circulating tumor DNA: Correlation with response to

534 checkpoint inhibitor-based immunotherapy. Clin. Cancer Res. 23, 5729-5736 (2017).

535 42. Robert, C. et al. Pembrolizumab versus ipilimumab in advanced melanoma (KEYNOTE-

536 006): post-hoc 5-year results from an open-label, multicentre, randomised, controlled, phase

5373 study. Lancet Oncol. 20, 1239-1251 (2019).

538 43. Hamid, O. et al. Final analysis of a randomised trial comparing pembrolizumab versus

539 investigator-choice chemotherapy for ipilimumab-refractory advanced melanoma. Eur. J.

$540 \quad$ Cancer 86, 37-45 (2017).

541 44. Overman, M. J. et al. 【CheckMate142試験】dMMR/MSI-H大腸癌に対するニボルマブ

542 ＋イピリムマブ療法の第II相試験. J. Clin. Oncol. 36, JCO.2017.76.990 (2018).

543 45. Le, D. T. et al. Phase II open-label study of pembrolizumab in treatment-refractory,

544 microsatellite instability-high/mismatch repair-deficient metastatic colorectal cancer:

545 KEYNOTE-164. in Journal of Clinical Oncology vol. 38 11-19 (American Society of

$546 \quad$ Clinical Oncology, 2020). 
medRxiv preprint doi: https://doi.org/10.1101/2020.11.25.20238865; this version posted November 29, 2020. The copyright holder for this preprint (which was not certified by peer review) is the author/funder, who has granted medRxiv a license to display the preprint in perpetuity.

It is made available under a CC-BY-ND 4.0 International license .

547 46. Overman, M. J. et al. Nivolumab in patients with metastatic DNA mismatch repair-deficient

548 or microsatellite instability-high colorectal cancer (CheckMate 142): an open-label,

549 multicentre, phase 2 study. Lancet Oncol. 18, 1182-1191 (2017).

550 47. Postow, M. A. et al. Nivolumab and ipilimumab versus ipilimumab in untreated melanoma.

$551 \quad$ N. Engl. J. Med. 372, 2006-2017 (2015).

552 48. Emens, L. A. Breast cancer immunotherapy: Facts and hopes. Clinical Cancer Research vol.

$553 \quad 24511-520(2018)$.

554 49. Eng, C. et al. Atezolizumab with or without cobimetinib versus regorafenib in previously

555 treated metastatic colorectal cancer (IMblaze370): a multicentre, open-label, phase 3,

556 randomised, controlled trial. Lancet Oncol. 20, 849-861 (2019).

557 50. McLeod, H. L., Mariam, A., Schveder, K. A. \& Rotroff, D. M. Assessment of adverse events

558 and their ability to discriminate response to anti-PD-1/PD-L1 antibody immunotherapy.

$559 \quad$ Journal of Clinical Oncology vol. 38 103-104 (2020).

560 51. Matson, V. et al. The commensal microbiome is associated with anti-PD-1 efficacy in

$561 \quad$ metastatic melanoma patients. Science 359, 104-108 (2018).

562 52. Gopalakrishnan, V. et al. Gut microbiome modulates response to anti-PD-1 immunotherapy

563 in melanoma patients. Science 359, 97-103 (2018).

564 53. El-Khoueiry, A. B. et al. Nivolumab in patients with advanced hepatocellular carcinoma

565 (CheckMate 040): an open-label, non-comparative, phase 1/2 dose escalation and expansion

$566 \quad$ trial. The Lancet 389, 2492-2502 (2017).

567 54. Rosenberg, J. E. et al. Atezolizumab in patients with locally advanced and metastatic

568 urothelial carcinoma who have progressed following treatment with platinum-based

569 chemotherapy: A single-arm, multicentre, phase 2 trial. The Lancet 387, 1909-1920 (2016). 
medRxiv preprint doi: https://doi.org/10.1101/2020.11.25.20238865; this version posted November 29, 2020. The copyright holder for this preprint (which was not certified by peer review) is the author/funder, who has granted medRxiv a license to display the preprint in perpetuity. It is made available under a CC-BY-ND 4.0 International license .

570 55. Doebler, P. \& Holling, H. Meta-Analysis of Diagnostic Accuracy with mada.

571 56. Guo, M. J. Package 'meta4diag' Title Meta-Analysis for Diagnostic Test Studies. (2018).

572 57. Gatsonis, C. et al. Meta-Analysis of Diagnostic and Screening Test Accuracy Evaluations:

573 Methodologic Primer. 187, 271-281 (2006).

574 58. Riley, R. D. et al. Multivariate meta-analysis using individual participant data. Res. Synth.

$575 \quad$ Methods 6, 157-174 (2015).

576 